\title{
Taking the Strain
}

A programme that people actually like! "Taking the Strain"

(five audio-cassettes and a workbook) brings benefits to clients and to counsellors, working through a broad range of issues concerning anxiety and stress.

Its approach, cognitive-behaviourally oriented, is constructive, pragmatic, and realistic. It really is

friendly to the user, as it introduces

opportunities for education, preparation, and application of stress management skills.

There are many ways that you could build it in to your repertoire. Whatever your profession, whatever your client group,

Taking the Strain"

would bring gains for all concemed

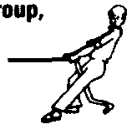

Details from:

Cestrian

Psychological Services

P.O. Box 70,

Tarporley, Cheshire.

CW6 90s.

\section{Behavioural Skills Course and}

Advanced Behavioural Skills Course

Training courses in Basic and Advanced Behavioural Skills.

One evening per week over one year at

Goldsmiths College, London.

Information and prospectus from:

Dr. Gordon Cree Applied Social Studies University of London Goldsmiths College Lewisham Way London SE14 6NW 

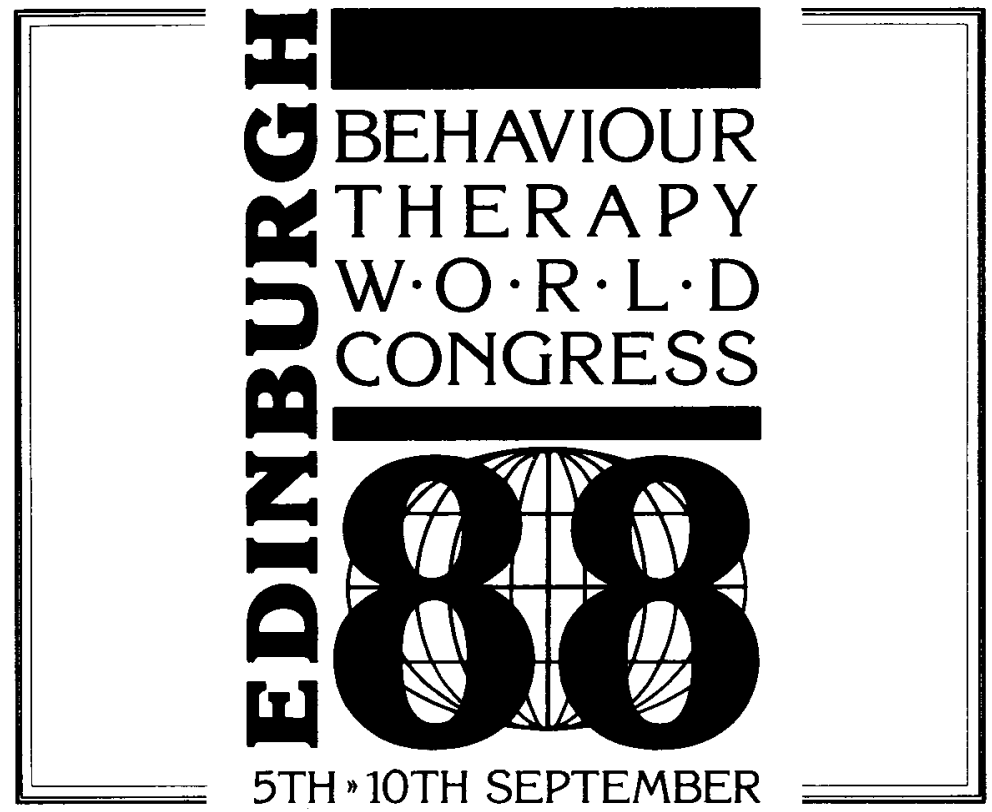

A Major International Multi-disciplinary Congress

Addressing Developments in the Application of

Behavioural Approaches to Areas of

Social , Psychological \& Medical Interest

PRE-CONGRESS WORKSHOPS

3RD \& 4TH SEPTEMBER

Further information -WCBT'88-ROD HOLLAND -59HEATH GARDENS TWICKENHAM·MIDDLESEX TW1 4LY·ENGLAND 


\section{CONTENTS}

ChANGE OF Editor

Miller, W. R., Sovereign, R. G. and Krege, B. Motivational Interviewing with Problem Drinkers: II. The Drinker's Check-up as a Preventive Intervention

McCrea, C. and Summerfield, A. B. A Pilot Study of the Therapeutic Usefulness of Videofeedback for Weight Loss and Improvement of Body Image in the Treatment of Obesity .......................

BEAIL, N. A Comparative Observational Study of the care provided in Hospital with the care provided at Home for Profoundly Multiply Handicapped Children

ONYETT, S. R. and TURPIN G. Benzodiazepine Withdrawal in Primary Care: A Comparison of Behavioural Group Training and Individual Sessions

Melin, L. and Linton, S. J. A Follow-up Study of a Comprehensive Behavioural Treatment Programme for Chronic Pain Patients

Jones, R. S. P. and BAKER, L. J. V. The Differential Reinforcement of Incompatible Responses in the Reduction of Self-Injurious Behaviour: A Pilot Study

MCCunE, N. Behavioural Family Intervention in Schizophrenia: A Case Study

BOOK REVIEWS 